\title{
Ground reaction force in basketball cutting maneuvers with and without ankle bracing and taping
}

\author{
Department of Physical Therapy, Speech and Occupational Therapy, School \\ of Medicine, Universidade de São Paulo, and Medical Rehabilitation Division, \\ Hospital das Clínicas, Universidade de São Paulo, São Paulo, Brazil
}

- Isabel de Camargo Neves Sacco

- Henrique Yuji Takahasi

- Eneida Yuri Suda

- Linamara Rizzo Battistella

- Cristianne Akie Kavamoto

- José Augusto Fernandes Lopes

- Jeane Cintra Peixoto de Vasconcelos

\section{INTRDDUCTION}

Sport injuries are one of the most common types of injury in modern Western societies. Their treatment is not only difficult, but also costly and lengthy. Therefore, the use of preventive measures is justified, from both an economic and a medical standpoint. ${ }^{1}$ For such prevention to be effective, the etiology, risk factors and main injury mechanisms need to be understood.

For basketball players, the ankle is the segment most frequently injured, and inversion sprains present the highest injury incidence rate. The ankle injury rate is 3.85 per 100 participations, with approximately half $(45.9 \%)$ of the players kept away from competition for a week or more. ${ }^{2}$ It is common to observe players using prophylactic measures, such as taping, wrapping, orthoses and other measures, either as sprain prevention or as rehabilitation.

A large number of studies have investigated the use of taping and orthoses as a prophylactic measure, usually with results defending the stance that bracing usage reduces injuries. However, its exact mechanism of action is still not well understood. Several studies in the literature have described external devices and taping, but with contradictory results. A few studies have investigated the role of proprioception and awareness of foot position in taping and orthoses for sprain prevention. A variety of methods were used by these authors, ranging from kinematics and electromyographic analyses to postural oscillation and stimulation of anesthetized cutaneous receptors of the lateral ligament complex. ${ }^{3}$

Some studies have analyzed the effects of orthoses and taping on athletic performance. Some of these found that external devices or taping impair activities such as jumping and running. ${ }^{4,5}$ One other study found that performance was improved among individuals with ankle instability by using semi-rigid orthoses, ${ }^{6}$ while in a study by Verbrugge ${ }^{7}$ these neither impaired nor improved athletic performance.

Electromyographic studies on the use of external devices and taping also describe different results. Some observed higher response latency or lower electromyographic (EMG) activity in fibular muscles while using orthoses and taping. ${ }^{8,9}$ Others found an improvement in reaction time or higher EMG activity in fibular muscles while using bracing. ${ }^{10,11}$

According to Canavan, ${ }^{12}$ taping and orthosis use by healthy athletes is unjustified. However, an external device or taping is recommended for competition-level athletes with a history of ankle injuries. This provides comfort and helps to control edema during the acute stage of a sprain.

Reductions in the injury rate may result from decreased muscle reaction time for the fibularis brevis in unstable ankles ${ }^{10}$ and also for ankle mechanoreceptor stimulations. ${ }^{6}$ The proprioceptive role of taping and orthoses seems to be greater than their restriction of total movement amplitude in ankles. ${ }^{6,10}$

There are few studies relating to ground reaction force (GRF) and external ankle devices or taping. Most of them studied movements that were less dynamic and functional, and did not find any differences in temporal or magnitude characteristics of GRF., ${ }^{9,13,14}$ One study found that the time to reach vertical GRF under orthosis and taping conditions was shorter than under control conditions during landing. ${ }^{15}$

Caulfield and Garrett ${ }^{16}$ examined the changes in timing and magnitudes of forces sustained by unstable ankles during jump landing, compared with healthy controls. They suggested that the changes in lateral and anterior peak forces observed are likely to

\section{ABSTRACT}

CONTEXT AND OBJECTIVE: In basketball, the most common injuries are ankle sprains. For this reason, players frequently use external ankle devices or taping as prophylactic and rehabilitation measures. The purpose of this study was to evaluate ground reaction force (GRF) responses in basketball players while performing typical cutting maneuvers with and without ankle bracing and ankle taping.

DESIGN AND SETTING: Comparative study with experimental design of single-group repeated measurements, at Medical Rehabilitation Division, Hospital das Clínicas, Faculdade de Medicina, Universidade de São Paulo.

METHODS: Vertical (Fy) and medial-lateral (Fz) GRF measurements were made under three conditions (taping, Aircast-type orthosis and basketball shoes alone), with analysis of peak forces at foot contact (Fymax 1, Fzmax 1, Fymax2 and Fzmax2), growth gradient (peak/time) (GG Fymaxl, GG Fzmax1, GG Fymax2 and GG Fzmax2) and impulse after foot contact.

RESULTS: Bracing significantly reduced Fymax2 and GG Fymax2. GG Fzmax 1 was significantly higher for the sport shoe condition than for the taping condition. Taping increased Fy in relation to the sport shoe at foot contact, but over a longer time interval, without increasing excessive ankle loading. Fz reached a peak in less time, which might generate greater inversion/eversion loading on a player's foot. The Aircast exerted better shock-absorbing effect than did the other two conditions, since it generated less vertical force over longer time intervals and smaller medial-lateral forces in relation to taping.

CONCLUSIONS: Ankle bracing and ankle taping action mechanisms are still unclear and therefore should be carefully prescribed. More studies are needed to clarify taping and bracing effects on sporting activities.

KEY WORDS: Biomechanics. Ankle. Movement. Kinetics. Motor activity. Basketball. 
result in repeated injury due to significant increases in stress on ankle joint structures, since the peak forces occurred significantly earlier in subjects with functional ankle instability.

In basketball, cutting maneuvers (quick eluding movements) are the mechanism responsible for approximately $30 \%$ of sprains. ${ }^{2}$ It has been suggested that when subjects perform cutting tasks during walking and running, the braking forces (anterior/posterior ground reaction force) increase during early stance. The higher braking forces are explained by the need to decelerate in preparation to cut toward the new plane of progression. These greater braking forces have been associated with a relative increase in quadriceps activation during the early stance of cutting tasks. ${ }^{17}$ However, the GRF patterns during cutting activities in subjects wearing ankle braces or taping have not been described to date.

\section{QBJECTIVE AND} HYPOTHESIS

The purpose of this study was to evaluate the dynamic GRF responses among professional basketball players while performing cutting maneuvers under controlled conditions: only using the sport shoes normally used for playing basketball and under two conditions of ankle support (taping and Aircast-type orthoses).

If ankle bracing or taping alters ankle stability, it would be expected that changes would occur in the timing and magnitudes of the forces sustained by the braced or taped ankle.
Our hypothesis was that the use of braces or taping would alter the vertical and mediallateral components of GRF during the impact and propulsion phases of basketball cutting maneuvers, and the temporal components of GRF, expressed as growth gradient (peak/time) for these forces and the impulses at $50 \mathrm{~ms}$ and $75 \mathrm{~ms}$ after foot contact on the platform.

\section{METHODS}

The sample was made up of a group of eight men who had played basketball for at least five years. At the time of the evaluation, they were between the ages of 17 and 25, healthy and without musculoskeletal or joint injuries or any functional or mechanical ankle instabilities. By means of an informed consent agreement, the subjects were made aware of the stages of the experimental protocol, which they read and through which they agreed to participate in the research. The protocol was assessed and approved by the Ethics Committee of the Physical Therapy, Speech and Occupational Therapy Department of the School of Medicine of Universidade de São Paulo.

The experimental protocol was developed at the Gait Laboratory of the Vergueiro Medical Rehabilitation Division and it consisted of two stages.

\section{PLAYERg' CHARAGTERIgTICE}

The players were evaluated by a physical therapist by means of clinical and functional tests on their ankles to verify the absence of mechanical or functional instability. ${ }^{18-23}$ Individuals with well-characterized complaints, either from the interview or functional testing, were considered to present functional instability. The functional test consisted of going down a staircase of 44 stairs; each stair was $18 \mathrm{~cm}$ long and $22 \mathrm{~cm}$ deep. The subject was asked to go down the staircase once, one step at a time with full contact of the foot shoe sole on the stairs. The time taken to go down the staircase was recorded using a chronometer. The results were classified as less than 18 seconds for the best results, from 18 to 20 seconds for the middle range, and over 20 seconds for the group with the worst results. ${ }^{24}$ Players going downstairs in over $20 \mathrm{~s}$ were not included in the study.

\section{BRACINE AND TAPINE}

The ankle bracing used in this study was the Aircast Stirrup-type orthosis (Aircast $I n c$.$) . This bracing device was chosen because$ basketball players frequently use it. ${ }^{5}$ The Aircast orthosis consists of two semi-rigid thermoplastic structures with a pre-inflated air cell of adjustable position and air volume. The orthosis surrounds the medial and lateral malleoli, reaching up to approximately six inches above the ankle joint and is fastened by Velcro ${ }^{\circledR}$ straps.

The taping technique consisted of applying non-elastic adhesive tape over the individual's skin. This technique has been considered to be the most efficient for joint
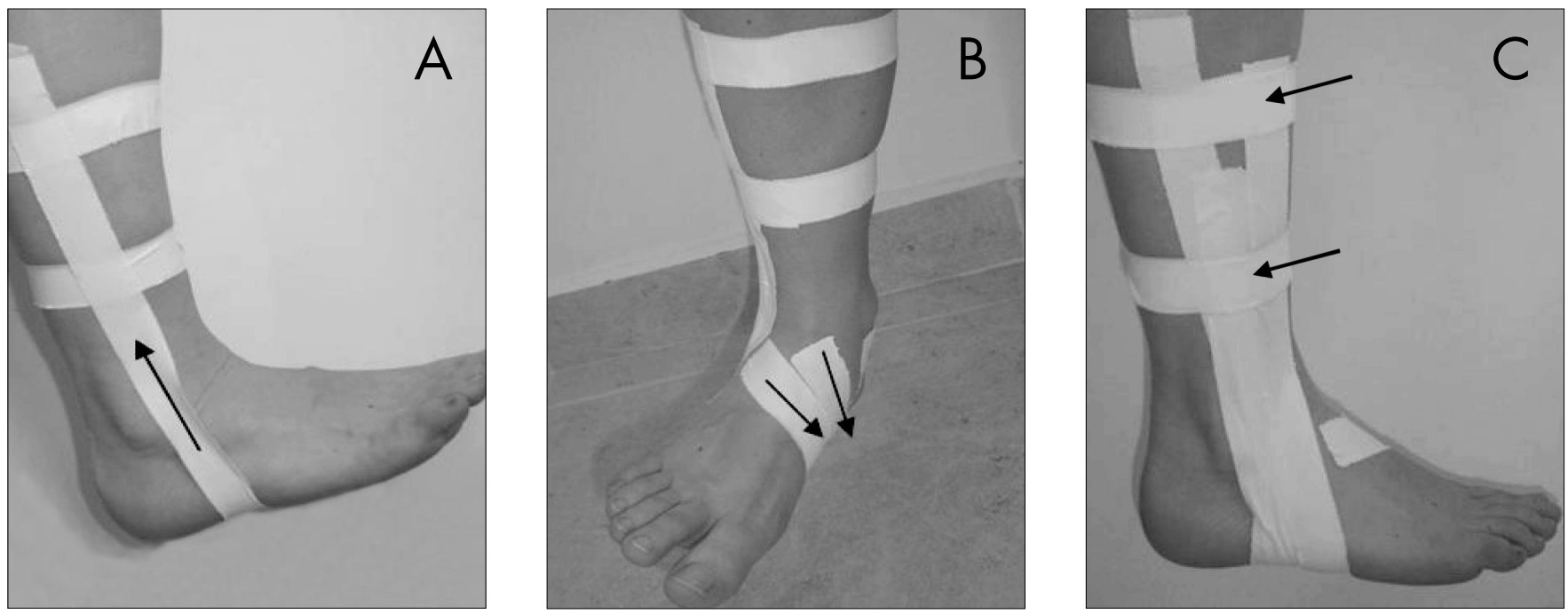

Figure 1. Schematic representation of taping technique. (A) Two strips of adhesive tape around the ankle about 5 and 10 centimeters above the lateral and medial malleoli were attached, and another tape strip was placed, passing over the medial malleolus, heel and lateral malleolus and attaching the tips of this tape to the support base, while maintaining the ankle in dorsiflexion and eversion. (B) Another two tape strips were applied to the instep, passing diagonally around the mid-foot, while also maintaining the ankle in dorsiflexion and eversion. A further strip was also placed across the instep, passing around the mid-foot, and over the lateral malleolus, and attaching it to the support base. (C) Another two tape strips were applied over the two support bases. 
stabilization. ${ }^{25}$ There are many ways of applying the tape. The technique used in the present study is illustrated in Figure 1. It consisted of, firstly, using two strips of adhesive tape around the ankle about 5 to 10 centimeters above the lateral and medial malleoli, and this was used as a support base. Then another tape strip was placed, passing over the medial malleolus, heel and lateral malleolus and attaching the tips of this tape to the support base, while maintaining the ankle in dorsiflexion and eversion. Another two tape strips were applied to the instep, passing diagonally around the mid-foot, while also maintaining the ankle in dorsiflexion and eversion. A further strip was also placed across the instep, passing around the mid-foot, and over the lateral malleolus, and attaching it to the support base. Finally, another two tape strips were applied over the two support bases.

During these trials, the sport shoes used by the subjects were those usually worn for playing basketball. The use of these sport shoes alone formed the control group (one individual was his own control).

\section{DYNAMICS}

During the second stage of the experimental protocol, the basketball cutting maneuver was dynamically evaluated. Cutting was chosen because it is the mechanism responsible for approximately $30 \%$ of sprains. ${ }^{2}$ This maneuver was performed by the players with and without the use of bracing or taping and under the control conditions of only using the normal sport shoes. The study design was as follows. The subjects were evaluated while performing cutting maneuvers on the force platform, and the change in direction was carried out using each player's dominant lower limb. The cutting movement was tested under each of these three conditions: Aircast-type bracing, taping and sport shoes alone. Each of these three conditions was repeated five times (five attempts), and the mean was calculated from these results.

This study used a force platform made by Applied Marine Technology, Inc., for acquisition and analysis of the vertical and anteroposterior and medial-lateral horizontal components of the ground reaction force. This platform was placed at ground level in a room with approximately 20 linear meters for the locomotion movements. Data were collected during the five attempts, each one with a sampling frequency of $500 \mathrm{~Hz}$ for a period of six seconds, which was compatible with these types of movements. ${ }^{26}$ Table 1 and Figure 2 describe the vertical and medial-lateral ground reaction force variables analyzed during this movement.

The vertical and medial-lateral ground reaction force variables for each study condition were normalized for the body weight of each subject and then filtered using a low-pass Butterworth filter with a $200 \mathrm{~Hz}$ cutoff frequency, as suggested by Roesler et al. ${ }^{26}$

\section{STATIBTICAL ANALYBIB}

The biomechanical variables studied were initially analyzed to verify the statistical data distribution through the Shapiro-Wilks $\mathrm{W}$ test, to identify non-parametric data. The variables were described for each trial condition in terms of their central trend measurement and error: mean and standard deviation. For variables originating from the questionnaire, the data for each trial condition were shown as percentages.

The ground reaction force and temporal variables did not show normal distribution, and therefore the three trial conditions were compared by means of the Kruskal-Wallis

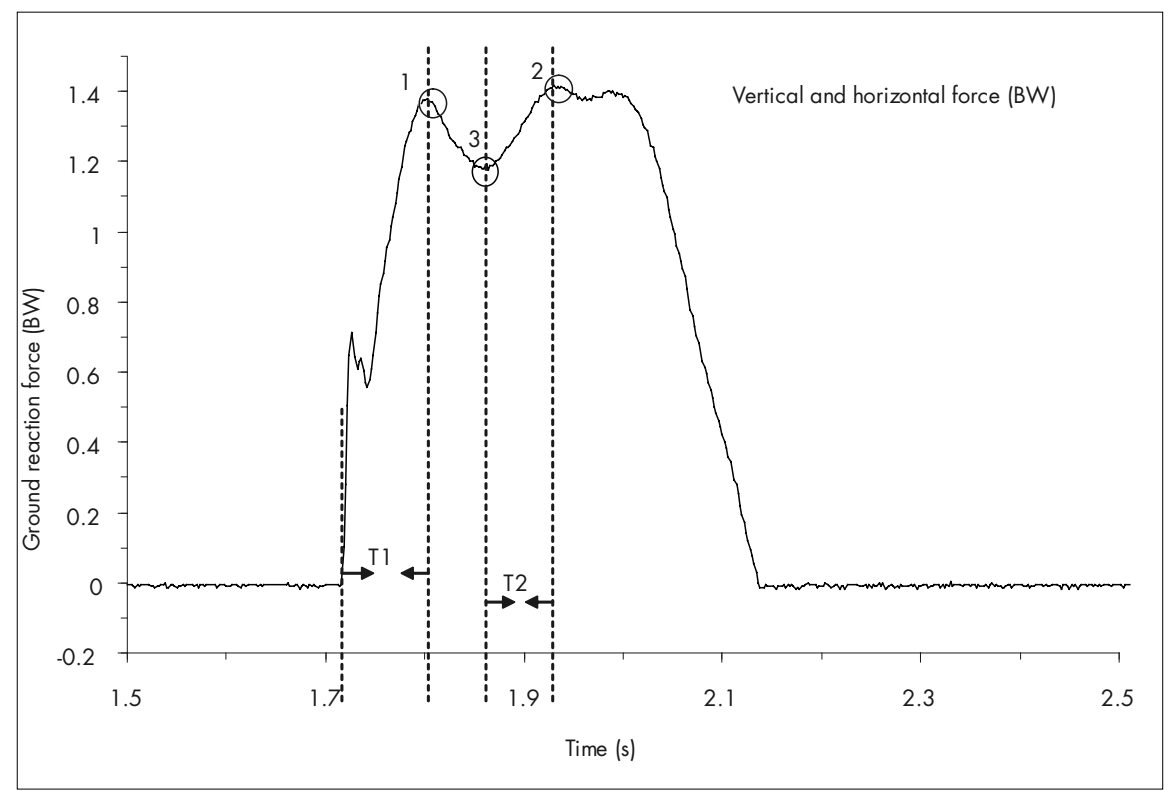

Figure 2. Graphic representation of vertical and horizontal forces during cutting maneuver with basketball shoes: (1) Fymaxl and Fzmax1, maximum vertical and medial-lateral forces at foot contact on the ground; (2) Fymax2 and Fzmax2, maximum vertical and medial-lateral forces at the moment of propulsion; (3) Fymin and Fzmin, minimum vertical and medial-lateral forces; (T1) time to reach Fymax 1 or Fzmax 1, (T2) time to reach Fymax2 or Fzmax2. BW = body weight.

Table 1. Description of the vertical and horizontal ground reaction force variables in cutting movements in basketball players

\begin{tabular}{|c|c|c|}
\hline Movement & Symbol & Description \\
\hline \multirow{7}{*}{ Cutting maneuver } & Fymaxl and Fzmax 1 & $\begin{array}{l}\text { Maximum vertical and medial-lateral forces } \\
\text { at foot contact on the ground }\end{array}$ \\
\hline & Fymax2 and Fzmax2 & $\begin{array}{c}\text { Maximum vertical and medial-lateral forces } \\
\text { at the moment of propulsion }\end{array}$ \\
\hline & Fymin and Fzmin & Minimum vertical and medial-lateral forces \\
\hline & GG Fymax 1 and Fzmax 1 & $\begin{array}{l}\text { GG for maximum vertical and medial-latera } \\
\text { forces at ground contact }\end{array}$ \\
\hline & GG Fymax2 and Fzmax2 & $\begin{array}{l}\text { GG for maximum vertical and medial-latera } \\
\text { forces at the moment of propulsion }\end{array}$ \\
\hline & Impulse after $50 \mathrm{~ms}$ & Impulse at 50 ms after ground contact \\
\hline & Impulse after $75 \mathrm{~ms}$ & Impulse at $75 \mathrm{~ms}$ after ground contact \\
\hline
\end{tabular}

$G G=$ growth gradient 
non-parametric inferential test, using the Mann-Whitney test as a post-hoc test, in which the latter was strong enough to prove individual differences. Differences with a significance level (p) lower than 0.05 were considered significant.

The Excel (Microsoft) and Statistica v.5.1 (Statsoft Inc.) software were used for handling the statistical treatment, while Origin v.5.0
(Microcal Software) software was used for the mathematical treatment of ground reaction force variables.

RESULTS

Table 2 shows the means, standard deviations and percentage distributions of the demographic and basketball-related variables for the subjects evaluated in this study.

Table 2. Means, standard deviations and percentage distributions of demographic variables, and description of basketball skill levels of subjects evaluated

\begin{tabular}{lc} 
Variables & Test group $(\mathbf{n}=\mathbf{8})$ \\
\hline Age (years) & $22.4 \pm 1.7$ \\
Weight $(\mathbf{k g})$ & $78.8 \pm 9.1$ \\
Height $(\mathbf{m})$ & $1.9 \pm 0.1$ \\
Body mass index (kg/m $)$ & $21.8 \pm 1.7$ \\
Time playing basketball (years) & $10.8 \pm 2.8$ \\
Training session time (hours) & $2 \pm 0$ \\
Weekly training frequency (times/week) (median) & 3 \\
Bracing and taping usage (\%) & 50 \\
\hline
\end{tabular}

Table 3. Mean and standard deviation for vertical ground reaction force during cutting maneuver in basketball, with sport shoe alone, taping and Aircast ankle bracing $(\mathrm{n}=8)$

\begin{tabular}{lcccc}
\hline Variables & Sport shoe alone & Aircast & Taping & p \\
\hline Fymax1 (BW) & $2.04 \pm 0.37$ & $2.03 \pm 0.43$ & $2.11 \pm 0.43$ & $>0.05$ \\
Fymax2 (BW) & $2.02 \pm 0.26$ & $1.44 \pm 0.13$ & $1.50 \pm 0.17$ & 0.0000 \\
Fymin (BW) & $1.20 \pm 0.19$ & $1.16 \pm 0.20$ & $1.14 \pm 0.25$ & $>0.05$ \\
GG Fymax1 (BW/s) & $45.64 \pm 22.06$ & $41.01 \pm 16.92$ & $44.91 \pm 21.54$ & $>0.05$ \\
GG Fymax2 (BW/s) & $29.20 \pm 27.05$ & $15.85 \pm 10.65$ & $18.64 \pm 15.59$ & 0.0490 \\
Impulse after 50 ms (N.s) & $0.05 \pm 0.01$ & $0.05 \pm 0.01$ & $0.05 \pm 0.02$ & $>0.05$ \\
Impulse after 75 ms (N.s) & $0.09 \pm 0.02$ & $0.08 \pm 0.02$ & $0.09 \pm 0.02$ & $>0.05$ \\
\hline
\end{tabular}

$G G=$ growth gradient; $B W=$ body weight; N.s = Newton. seconds; Fymax $1=$ maximum vertical and medial-lateral forces at foot contact on the ground; Fymax $2=$ Maximum vertical and medial-lateral forces at the moment of propulsion; Fymin = Minimum vertical and medial-lateral forces; $G G$ Fymax $1=G G$ for maximum vertical and medial-lateral forces at ground contact; $G G$ Fymax2 = GG for maximum vertical and medial-lateral forces at the moment of propulsion.

Table 4. Mean and standard deviation of horizontal ground reaction force during cutting in basketball with and without ankle bracing: sport shoe, taping and Aircast $(\mathrm{n}=8)$

\begin{tabular}{lcccc}
\hline Variables & Sport shoe alone & Aircast & Taping & $p$ \\
\hline Fzmax1 (BW) & $1.53 \pm 0.35$ & $1.54 \pm 0.39$ & $1.54 \pm 0.42$ & $>0.05$ \\
Fzmax2 (BW) & $0.85 \pm 0.40$ & $0.95 \pm 0.26$ & $1.00 \pm 0.31$ & $>0.05$ \\
Fzmin (BW) & $0.79 \pm 0.12$ & $0.82 \pm 0.21$ & $0.81 \pm 0.19$ & $>0.05$ \\
GG Fzmax1 (BW/s) & $27.36 \pm 11.19$ & $30.73 \pm 11.01$ & $35.38 \pm 16.78$ & 0.0433 \\
GG Fzmax2 (BW/s) & $10.75 \pm 10.61$ & $11.44 \pm 11.56$ & $14.43 \pm 16.19$ & $>0.05$ \\
Impulse 50 ms (N.s) & $0.03 \pm 0.01$ & $0.03 \pm 0.01$ & $0.03 \pm 0.01$ & $>0.05$ \\
Impulse 75 ms (N.s) & $0.07 \pm 0.02$ & $0.02 \pm 0.02$ & $0.07 \pm 0.02$ & $>0.05$
\end{tabular}

$G G=$ growth gradient; $B W=$ body weight; N.s = Newton. seconds; Fymax $1=$ maximum vertical and medial-lateral forces at foot contact on the ground; Fymax $2=$ Maximum vertical and medial-lateral forces at the moment of propulsion; Fymin = Minimum vertical and medial-lateral forces; $G G$ Fymax $1=G G$ for maximum vertical and medial-lateral forces at ground contact; $G G$ Fymax2 $=G G$ for maximum vertical and medial-lateral forces at the moment of propulsion.

In this study all subjects were male, with a mean age of $22.4 \pm 1.7$ years. The subjects had a mean body mass index of $21.8 \pm 2.7 \mathrm{~kg} / \mathrm{m}^{2}$. The length of time for which they had participated in basketball was $10.8 \pm 2.8$ years. The mean frequency of training sessions was $3 \pm 1$ times per week, with a mean duration of two hours. With regard to the position they played, only two players were guards, four played as centers and seven as forwards, and of the eight subjects, five played in more than one position. A large majority of these subjects $(87.5 \%$, or $7 / 8)$ played basketball within the adult ranking while only one (12.5\%) played within the 17-year-old ranking. Concerning their basketball skill levels, one player $(12.5 \%)$ played professionally, one player (12.5\%) played at the amateur level and the other $75 \%(6 / 8)$ played college basketball.

Fifty percent of the players use regularly external devices or taping during games and training sessions, yet $75 \%$ of the players had already suffered ankle sprains and, of these, $66 \%$ had injured both ankles.

Figure 3 and Table 3 show the mean and standard deviations for vertical ground reaction force variables during cutting maneuvers under the three trial conditions. For the sport shoe condition, the second peak force (Fymax2) was significantly higher than for the taping and Aircast conditions $(\mathrm{p}=0.0000)$, but there was no difference in cutting maneuvers between the taping and Aircast conditions $(p>0.05)$. With regard to the Fymax2 growth gradient, there were significant differences between the three conditions $(p=0.0490)$, in which the value found for the sport shoe condition was higher than the values for Aircast $(\mathrm{p}=0.0020)$ and taping $(0.0121)$. The gradient values for the taping and Aircast conditions did not show any statistical difference between them ( $\mathrm{p}=0.8778)$.

Figure 4 and Table 4 show the mean and standard deviation of medial-lateral ground reaction force variables during cutting maneuvers while using bracing, taping and sport shoes alone. There were no significant differences with respect to force magnitudes between these three conditions. However, the Fzmax 1 growth gradient was significantly lower for the sport shoe condition than for the taping condition $(\mathrm{p}=0.0433)$.

DISCUSSIDN

The mean age in this study (22 years) shows that the subjects were all young individuals, which lowered the likelihood of chronic diseases related to decreased mobility. A large majority of the subjects $(87.5 \%)$ played 
basketball within an adult ranking, at college level. Moreover, all the subjects had negative results from clinical tests for functional and mechanical instability, thus demonstrating that none of them had any kind of ankle joint instability that could alter the results.

The mean body mass index (BMI) was $21.8 \mathrm{~kg} / \mathrm{m}^{2}$, which is within normal limits (i.e. between 20 and 25), ${ }^{27}$ thereby eliminating the possibility that there might have been excessive loading on the joints, or other abnormalities resulting from states of excessive weight.

A considerable percentage of the subjects $(50 \%)$ were regularly using external devices or taping during games and training sessions as a way of preventing ankle sprains. Yet we observed in this study that most of the players (75\%) had already suffered ankle sprains and, of these, $66 \%$ had injured both ankles. This demonstrates that these are very common basketball injuries, and that there is therefore a need to improve the knowledge of how to prevent this kind of injury, and how such injuries are related to the types of maneuvers made by players.

A study by McKay et al. ${ }^{28}$ did not find any correlations for gender, age, mass, height and training frequency versus the incidence of ankle injuries. However, it is important to note that the sport of basketball typically presents training overload and this was the case for the players evaluated in that study. Such training overload would increase the musculoskeletal loading and, consequently, place stress on ankles and favor the incidence of injuries.

One study analyzed ground reaction force in lateral displacement and found no differences between control conditions and conditions using orthoses and taping. However, in the present study there were statistically significant differences in the vertical and medial-lateral components of the ground reaction force.

In considering the cutting maneuver, it was observed that under the taping conditions, the vertical force magnitude (Fymax 1 ) at the moment of foot contact with the ground tended to be higher than under the conditions of sport shoes alone and Aircast, and that the growth gradient (GG) for this force (GG Fymax1) tended to be higher solely in relation to Aircast. Although taping produced higher vertical force in relation to the sport shoe alone, the GG values for both conditions remained similar. That is, taping increased the vertical peak force, but over a proportionally longer time interval. The consequent interpretation for this is that the

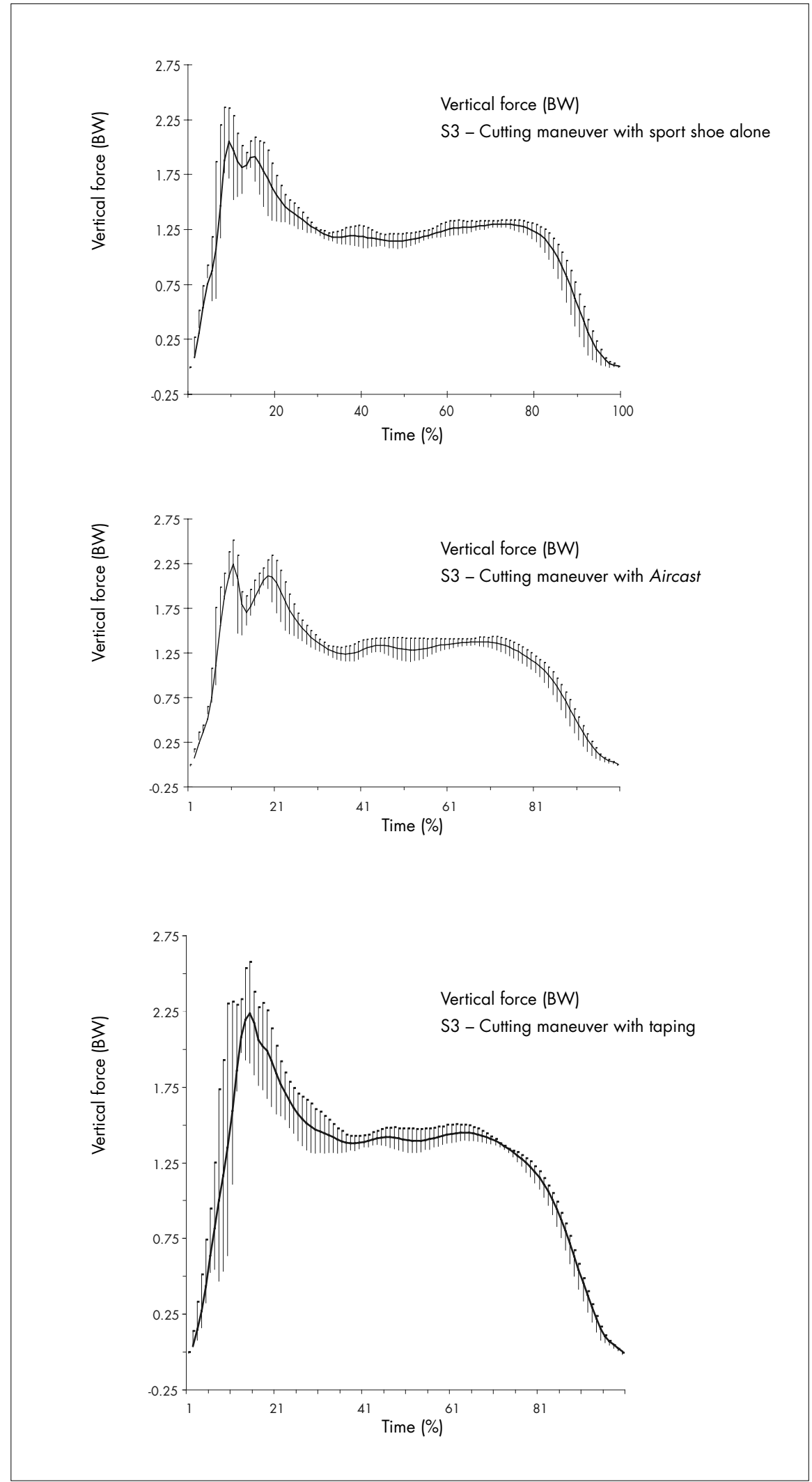

Figure 3. Graphic representation of mean and standard deviation for vertical ground reaction force during cutting maneuver in basketball with sport shoe alone, Aircast and taping for subject 3 . BW $=$ body weight. 


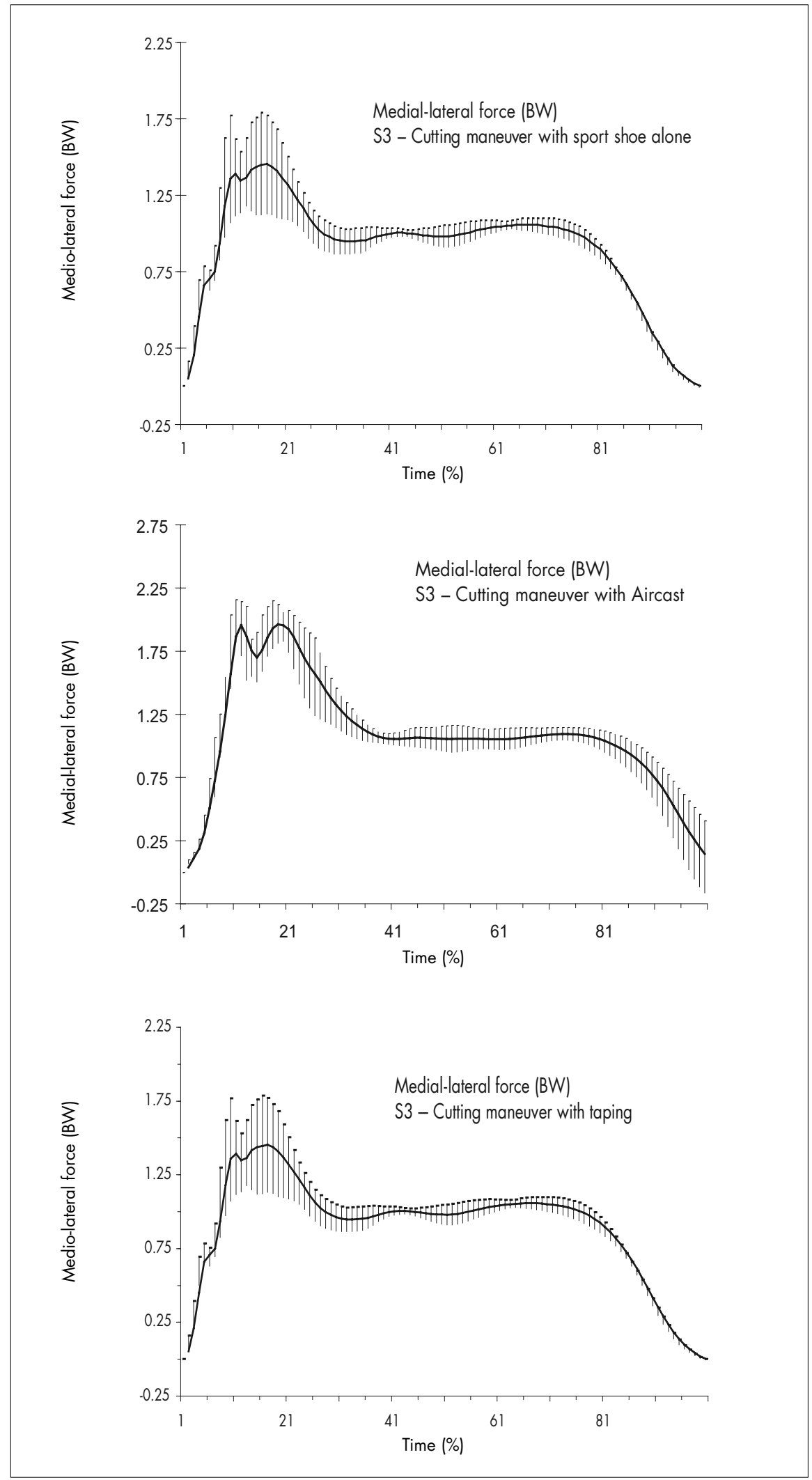

Figure 4. Graphic representation of mean and standard deviation for horizontal ground reaction force during cutting maneuver in basketball with sport shoe alone, Aircast and taping for subject 3 . BW $=$ body weight. excessive loading under this condition did not change. In relation to Aircast, taping tended to produce a higher vertical force value over a shorter time interval during ground impact. The growth gradient for vertical force under the taping condition had higher inclination than for Aircast, thus indicating that this bracing was exerting a better shock-absorbing effect than were the sport shoe alone and taping, and consequently, less loading on the more distal joints.

From analysis of the medial-lateral component of the cutting maneuver, it was found that, for taping, the growth gradient for this force at ground contact (GG Fzmax1) was also significantly higher than for the sport shoe alone $(\mathrm{p}=0.0433)$ and tended to be higher than for Aircast, although the medial-lateral force values were similar. This result is in agreement with the earlier study by Cordova et al., which did not find any differences in impact peak force magnitude (foot contact with the ground) for the medial-lateral component during lateral displacements that were similar to cutting maneuvers. However, these authors did not analyze the time needed to reach this peak force at the moment of ground contact. The increased GG Fzmax1 under the taping condition that was observed in the present study means that the use of this stabilizing technique decreased the time to reach the medial-lateral peak force. This higher growth gradient for medial-lateral force may result from a more rigid ankle, which would have smaller inversion and eversion movement amplitudes as a result of taping.

On the other hand, a high GG Fzmax1 value may signify more excessive loading on the ankle and lower limb joints over a medium and long-term basis. Bracing usage would limit the time for external forces to act on the small movement amplitude available for the joint, thus making the other foot and ankle structures absorb greater forces. ${ }^{9}$ Furthermore, higher compressive forces might be generated, thereby resulting in greater injury risk. Although the Aircast and taping conditions did not show any statistical difference, these conditions showed a tendency towards higher medial-lateral peak force on the impact and propulsion moments (Fzmax1 and Fzmax2) and greater growth rates for these forces. As previous stated by Riemann et al., ${ }^{15}$ these alterations indicate that during dynamic activities the musculoskeletal structures of the body may be subjected to loads within shorter time periods.

At the propulsion phase of the cutting maneuver, the sport shoe condition showed 
significantly higher vertical force values (Fy$\max 2)$ than did the taping $(\mathrm{p}=0.0000)$ and Aircast (0.0000) conditions. The force growth gradient (GG Fymax2) was also significantly higher than for taping $(\mathrm{p}=0.0121)$ and Aircast $(\mathrm{p}=0.0020)$. Bracing produced smaller vertical forces over longer time intervals, i.e. after the minimum vertical force moment (Fymin) the vertical GRF peaks for impulsion were reached in less time for taping and Aircast, in comparison with the sport shoe. But the taping and Aircast conditions were shown to be significantly similar. As mentioned earlier, it can be interpreted that bracing might be reducing the excessive loading on the vertical joint at the moment of impulsion during the cutting maneuver, a situation that the sport shoe alone was unable to implement. This finding is in agreement with the study by Anderson et al., ${ }^{29}$ which suggested that the use of non-rigid orthoses slows the inversion movement. Therefore, the musculoskeletal system might have more time to respond to the demands from external forces, thereby generating less excessive loading on the foot and ankle structures.

Concerning the medial-lateral force at the propulsion phase, the taping condition tended to show a higher peak force value in comparison to the Aircast condition, and the latter was higher than for the sport shoe condition. The growth gradient for taping also tended to be higher than for the other two conditions. It can be considered that, when taping is used, at the moment of propulsion there are more foot movement instabilities, which is unexpected, since this bracing should serve to stabilize medial-lateral maneuvers.

In summary, at the moment the ground receives the load, taping increased the vertical force in relation to the sport shoe alone, but over a longer time interval, without increas- ing excessive ankle loading. On the other hand, in relation to medial-lateral force, the taping condition reached a peak in less time, which might generate greater inversion/eversion loading on the player's foot. In this same maneuver, the Aircast exerted better shock-absorbing effect than did the other two conditions, since it generated less vertical force over a longer time interval and smaller medial-lateral forces than did taping. With regard to propulsion during the cutting maneuver, bracing reduced the magnitude and increased the time needed to reach vertical peak force, thereby allowing more time for adjustments and adaptations of the muscle control system. But for medial-lateral force, taping produced higher peak forces in less time than did the other two conditions, thereby generating more excessive loading during inversion/eversion.

The search for decreasing the mediallateral forces is leading towards an increase in other GRF components, i.e., increases in the vertical components of this force, for example. According to Cordova et al., ${ }^{9}$ this would cause increased compressive forces on the skeletal system. These alterations indicate that during dynamic activity the musculoskeletal structures of the body may be subjected to loads within shorter time periods. Whether these effects are detrimental over time remains speculative at this point and requires further research.

FINAL CONSIDERATIONS

The effects of prophylaxis on sprain prevention and the use of such measures for sprain treatment have already been comprehensively described in the literature. However, few studies have analyzed ground reaction forces during dynamic activities with ankle bracing or taping, and most of these did not find differences between control and study conditions.

One alternative to using ankle bracing or taping for preventing injuries would be muscle and proprioception training to improve neuromuscular response during ankle mobilization. Increasing flexibility would allow the ankle to reach a certain movement amplitude without reaching the limit at which injury occurs; increasing muscle strength would allow muscles to resist the maneuver that might result in ankle sprains; decreasing neuromuscular time response would allow an individual to react more quickly to a possible injury. ${ }^{30}$

Several studies in the literature have given ambiguous evidence concerning the effects of bracing and taping on GRF, performance, balance and muscle activity. ${ }^{30}$ The mechanisms by which external ankle devices and taping act are still unclear and more studies are needed in order to understand their effects on sporting activities. It is therefore suggested that coaches and physical therapists should be careful in prescribing bracing devices or taping for healthy athletes.

\section{CONCLUSIONS}

In the present study, it was observed that bracing and taping generated alterations in vertical and medial-lateral ground reaction forces between taping, Aircast and control conditions. As expected, bracing and taping attenuated vertical or mediallateral ground reaction force components in some instances, while on the other hand increasing others, which would lead to increased compressive and inversion/eversion forces on the skeletal system by restricting joint mobility. Therefore, although players frequently use bracing devices or taping, whether these effects are detrimental over time also remains speculative at this point and requires further research.
1. Parkkari J, Kujala UM, Kannus P. Is it possible to prevent sports injuries? Review of controlled clinical trials and recommendations for future work. Sports Med. 2001;31(14):985-95.

2. McKay GD, Goldie PA, Payne WR, Oakes BW. Ankle injuries in basketball: injury rate and risk factors. Br J Sports Med. 2001;35(2):103-8.

3. Callaghan MJ. Role of ankle taping and bracing in the athlete. Br J Sports Med. 1997;31(2):102-8.

4. Burks RT, Bean BG, Marcus R, Barker HB. Analysis of athletic performance with prophylactic ankle devices. Am J Sports Med. 1991;19(2):104-6

5. MacKean LC, Bell G, Burnham RS. Prophylactic ankle bracing vs. taping: effects on functional performance in female basketball players. J Orthop Sports Phys Ther. 1995;22(2):77-81.

6. Hals TM, Sitler MR, Mattacola CG. Effect of a semi-rigid ankle stabilizer on performance in persons with functional ankle instability. J Orthop Sports Phys Ther. 2000;30(9):552-6.

7. Verbrugge JD. The effects of semirigid Air-Stirrup bracing vs. adhesive ankle taping on motor performance. J Orthop Sports Phys Ther. 1996;23(5):320-5.
8. Perrin PP, Bene MC, Perrin CA, Durupt D. Ankle trauma significantly impairs posture control--a study in basketball players and controls. Int J Sports Med. 1997;18(5):387-92.

9. Cordova ML, Armstrong CW, Rankin JM, Yeasting RA. Ground reaction forces and EMG activity with ankle bracing during inversion stress. Med Sci Sports Exerc. 1998; 30(9):1363-70.

10. Karlsson J, Andreasson GO. The effect of external ankle support in the chronic lateral ankle joint instability. An eletromyographic study. Am J Sports Med. 1992;20(3):257-61.

11. Geyer M, Siebert WE. Komplexe Bewegungsanalyse: dynamische Untersuchung zum Effekt des Tapeverbandes auf die Pronation beim Hochsprung mit dreidimensionaler Bewegungsanalyse und Elektromyographie. [Complex movement analysis: dynamic study of the effect of a tape bandage on pronation in high-jumping with three-dimensional movement analysis and electromyography]. Sportverletz Sportschaden. 1991;5(2):103-7.

12. Canavan PK. Rehabilitation in Sports Medicine. New York: McGraw-Hill Medical; 1998.
REFERENCES

13. Hamill J, Knutzen KM, Bates BT, Kirkpatrick G. Evaluation of two ankle appliances using ground reaction force data. J Orthop Sports Phys Ther. 1986;7(5):244-9.

14. McIntyre DR, Smith MA, Denniston NL. The effectiveness of strapping techniques during prolonged dynamic exercises. J Athl Train. 1983;18:52-5.

15. Riemann BL, Schmitz RJ, Gale M, McCaw ST. Effect of ankle taping and bracing on vertical ground reaction forces during drop landings before and after treadmill jogging. J Orthop Sports Phys Ther. 2002;32(12):628-35.

16. Caulfield B, Garrett M. Changes in ground reaction force during jump landing in subjects with functional instability of the ankle joint. Clin Biomec (Bristol, Avon). 2004; 19(6):617-21.

17. Houck J. Muscle activation patterns of selected lower extremity muscles during stepping and cutting tasks. J Electromyogr Kinesiol. 2003;13(6):545-54

18. Baptista CA, Filho JA, Andrade BJ. Exame clínico geral préparticipação. In: Ghorayeb N, Barros T, editors. O exercício. São Paulo: Atheneu; 1999. p. 51-8. 
19. Ribeiro CZP, Akashi PMH, Sacco ICN, Pedrinelli A. Relationship between postural changes and injuries of the locomotor system in indoor soccer athletes. Rev Bras Med Esporte. 2003;9(2):98-103.

20. Fu FH, Stone DA. Sports injuries: mechanisms, prevention, treatment. Baltimore: Williams \& Wilkins; 1994.

21. Konradsen L, Olesen S, Hansen HM. Ankle sensorimotor control and eversion strength after acute ankle inversion injuries. Am J Sports Med. 1998;26(1):72-7.

22. Safran MR, Benedetti RS, Bartolozzi AR $3^{\text {rd }}$, Mandelbaum BR. Lateral ankle sprains: a comprehensive review. part 1: etiology, pathoanatomy, histopathogenesis, and diagnosis. Med Sci Sports Exerc. 1999;31(7Suppl):S429-37.

23. Hockenbury RT, Sammarco GJ. Evaluation and treatment of ankle sprains. Clinical recommendations for a positive outcome. Phys Sportsmed. 2001;29(2):569-81

24. Kaikkonen A, Kannus P, Järvinen M. A performance test protocol and scoring scale for the evaluation of ankle injuries. Am J Sports Med. 1994;22(4):462-9.
25. Ferreira PH. A eficácia de tornozeleiras e bandagens funcionais no controle do equilíbrio dinâmico. In: Anais. VII Congresso Brasileiro de Biomecânica; 1997, Mai 23-26, Campinas; 1997. p. 407-12.

26. Roesler CRM, Iturrioz I. Identificação do conteúdo de frequiências presente na força de reação do solo medida com plataforma de forças. [Frequency present in reaction force of the floor measure with force platform]. Rev Bras Biomec. 2002;3(4):51-6.

27. McArdle WD, Katch FI, Katch VL. Fisiologia do exercício: energia, nutriçăo e desempenho humano. 4 a ed. Rio de Janeiro: Guanabara Koogan; 1998.

28. McKay GD, Goldie PA, Payne WR, Oakes BW, Watson LF. A prospective study of injuries in basketball: a total profile and comparison by gender and standard of competition. J Sci Med Sports. 2001;4(2):196-211.

29. Anderson DL, Sanderson DJ, Hennig EM. The role of external nonrigid ankle bracing in limiting ankle inversion. Clin J Sports Med. 1995;5(1):18-24.
30. Hume PA, Gerrard DF. Effectiveness of external ankle support. Bracing and taping in rugby union. Sports Med. 1998;25(5):285-312

\author{
Sources of funding: None \\ Conflict of interest: Non \\ Date of first submission: December 28, 2004 \\ Last received: August 18, 2006 \\ Accepted: August 21, 2006
}

AUTHOR INFRRMATION

Isabel de Camargo Neves Sacco, PhD. Deparment of Physical Therapy, Speech and Occupational Therapy, School of Medicine, Universidade de São Paulo, São Paulo, Brazil.

Henrique Yuji Takahashi, PT. Department of Physical Therapy, Speech and Occupational Therapy, School of Medicine, Universidade de São Paulo, São Paulo, Brazil.

Eneida Yuri Suda, PT. Postgraduate student in the Department of Physical Therapy, Speech and Occupational Therapy, School of Medicine, Universidade de São Paulo, São Paulo, Brazil.

Linamara Rizzo Battistella, PhD. Gait Laboratory, Medical Rehabilitation Division, Hospital das Clínicas, School of Medicine, Universidade de São Paulo, São Paulo, Brazil.

Cristianne Akie Kavamoto, MD. Gait Laboratory, Medical Rehabilitation Division, Hospital das Clínicas, School of Medicine, Universidade de São Paulo, São Paulo, Brazil.

José Augusto Fernandes Lopes, MSc. Gait Laboratory, Medical Rehabilitation Division, Hospital das Clínicas, School of Medicine, Universidade de São Paulo, São Paulo, Brazil.

Jeane Cintra Peixoto de Vasconcelos, PT. Gait Laboratory, Medical Rehabilitation Division, Hospital das Clínicas, School of Medicine, Universidade de São Paulo, São Paulo, Brazil.

\section{Address for correspondence:}

Isabel de Camargo Neves Sacco

Departamento de Fisioterapia, Fonoaudiologia e

Terapia Ocupacional da Faculdade de Medicina da

Universidade de São Paulo (FMUSP)

Rua Cipotânia, 51 - Cidade Universitária

São Paulo (SP) - Brasil - CEP 05360-000

Tel. (+55 11) 3091-7464 - Fax (+55 11) 3091-7462

E-mail: icnsacco@usp.br

\section{Análise da força de reação do solo durante o cutting no basquetebol com e sem o uso de implementos} no tornozelo

CONTEXTO E OBJETIVO: A lesão mais comum no basquetebol é a entorse de tornozelo. Assim, os atletas freqüentemente utilizam suportes externos como medidas profiláticas. O objetivo deste estudo é avaliar as respostas da força de reação do solo (FRS) durante a execução do movimento de cutting do basquetebol com e sem acessórios de tornozelo.

TIPO DE ESTUDO E LOCAL: Estudo comparativo. Delineamento experimental de grupo único com medidas repetidas; Divisão de Medicina de Reabilitação, Hospital das Clínicas, Faculdade de Medicina da Universidade de São Paulo, Brasil.

MÉTODOS: Foram colhidas as forças vertical (Fy) e médio-lateral $(\mathrm{Fz})$ em três condições (bandagem, Aircast e calçado esportivo) e analisados os picos de força e de propulsão no contato com o solo (Fymax 1, Fzmax1, Fymax2 e Fzmax2), o gradiente de crescimento (pico/tempo) (GC Fymax1, GC Fzmax1, GC Fymax2 e GC Fzmax2) e o impulso após o contato.

RESULTADOS: Os acessórios reduziram significativamente Fymax2 e GC Fymax2. GC FZmax 1 foi maior na situação com tênis quando comparado com bandagem. No momento do impacto, a bandagem aumentou a Fy em relação ao calçado, mas em um intervalo de tempo maior, não aumentando a carga articular. Fz atingiu um pico em menor tempo, podendo gerar maior carga eversora/inversora. O Aircast exerceu um melhor efeito de absorção de impacto, pois gera menor Fy em um maior intervalo de tempo.

CONCLUSÕES: Apesar do uso freqüente deste tipo de recurso pelos atletas, seu mecanismo de ação ainda é confuso. Mais estudos são necessários para esclarecer seus efeitos nas atividades esportivas a longo prazo.

PALAVRAS-CHAVE: Biomecânica. Tornozelo. Cinética. Atividade motora. Movimento. Basquetebol. 